\title{
Using 3R Framework to Promote the Teaching Reform of Color Composition
}

\author{
Shi Wenwen \\ School of Cultural Communication and Design, Zhejiang University of Finance \& Economics Dongfang College, Hangzhou, China

\section{Email address:} \\ 3170858228@qq.com

\section{To cite this article:} \\ Shi Wenwen, Using 3R Framework to Promote the Teaching Reform of Color Composition. Teacher Education and Curriculum Studies. \\ Vol. 5, No. 4, 2020, pp. 161-166. doi: 10.11648/j.tecs.20200504.13
}

Received: December 9, 2020; Accepted: December 21, 2020; Published: December 28, 2020

\begin{abstract}
In the traditional teaching process, it was found that the basic design course "color composition" in environmental design major had the following problems: assignments were rigid and lack of creativity; the course were lack of applicability and hardly integrated with the major. Through literature review, field research, professional training, practical demonstration and questionnaire survey, the author summarizes the $3 \mathrm{R}$ framework to promote teaching reform: refining teaching contents, raising teaching procedures and renovating teaching methods. It is aimed to build a knowledge framework, set up teaching procedures scientifically and innovatively, optimize and reform teaching methods, raise the objectivity of teaching evaluation, so as to improve students' learning enthusiasm, increase their creative inspiration of homework, and form a more effective learning closed loop. Each aspect comes with several steps to solve the above problems, and they are classifying knowledge points, integrating with specialty, employing modular teaching methods and theme teaching method, including five senses, combining teaching with practice, assessment as learning, and focusing on teamwork. After the initial exploration of the course, teaching analysis and summary, classroom practice, the final goal of the reform is achieved. It is proved that students have a new understanding of color composition as well as their major after this reform.
\end{abstract}

Keywords: Framework, Teaching Reform, Refining Teaching Contents, Raising Teaching Procedures, Renovating Teaching Methods, Classroom Practice

\section{Introduction}

\subsection{Background}

Color composition is a basic course for the freshmen in environment design major which takes color as the fundamental visual element to compose [1]. Color composition, together with plane composition and 3D composition, are considered as the three major components. It has always been an indispensable "basic design" [2] for art design majors. The purpose of the course includes the following three points:

1. Lay the design foundation for students to engage in the study of environment design.

2. Improve students' aesthetics and design ability.

3. Cultivate students' perception of color design [3].

\subsection{Status Quo and Problems}

\subsubsection{Status Quo of the Course}

The three-week course is a subcategory for the design course. The time span is short and the teaching content is intense, which is not conducive to students' acceptance and memory. Since closed-book test is not needed, the evaluation is composed of daily performance and the final assignment. Thus students' mastery of professional knowledge becomes a problem. In addition, the assessment of learning is the main method to evaluate the learning effect of students. Teachers' subjective evaluation has a great impact on the performance, therefore, the objectivity of evaluation is questionable.

\subsubsection{Analysis of the Students}

Dongfang College of Zhejiang University of Finance and Economics is an application-oriented independent college. The characteristics of students are as follows: lack of self-control, self-discipline and self-management; passive and realistic motivation; bad study habits; procrastination and lack of attention. However, the students also boast active thinking. They are bold and lively and have various social activities and 
student society activities.

\subsubsection{Problems in the Course}

i. Assignments are rigid and lack of creativity

Rigid assignments are the reasons for students' lack of motivation in study, which leads to the decline of academic achievement. Each lecture, the teacher requires students to do a lot of boring color shift and color contrast [4] practice, which exhausted students' participation and enthusiasm.

ii. Low integration between the assignments and the profession

Although color composition is the basis of all kinds of professional courses, with the deepening of learning, its professionalism should be more prominent. But the aimless practice not only impedes the students' professional accomplishment, but also develops their negative attitudes towards the course, which seriously affect the study.

iii. Lack of applicability

The purpose of professional basic courses is to consolidate students' professional foundation, as well as help them apply the knowledge into future practice. Getting the basic method of constitution through boring constitution practice, students still don't know how to use it and transfer the knowledge to other situations, thus lead to the disconnection to the following professional classes.

\section{Methodology}

Based on the above status quo and problems, I have established the teaching reform idea of 3R framework, shortened for Refining Teaching Contents, Renovating Teaching Methods, Raising Teaching Arrangements. See Figure 1.

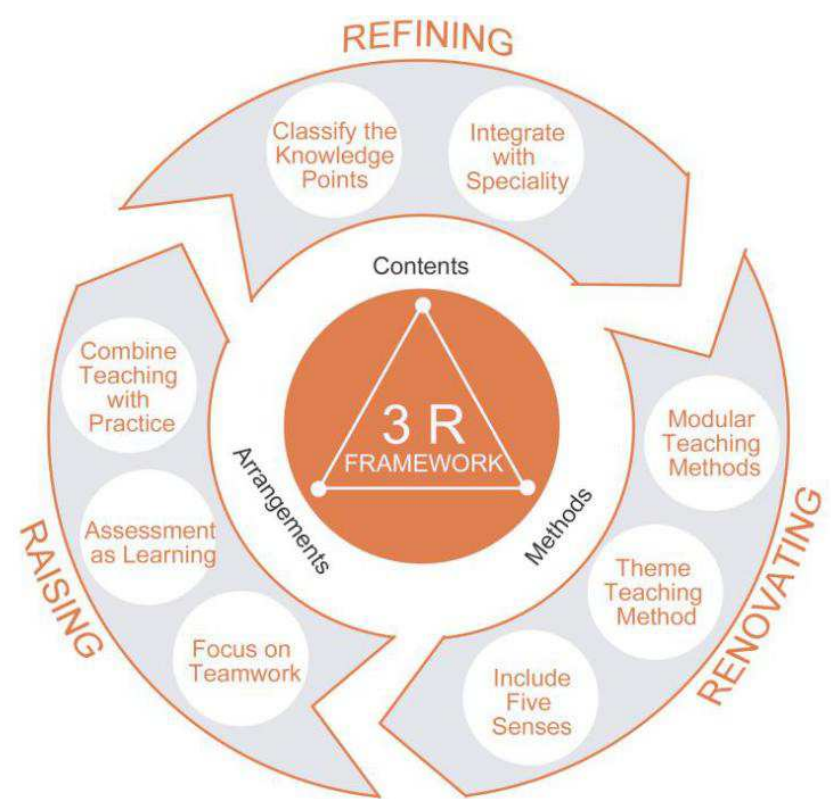

Figure 1. 3R Framework.

\subsection{Refining Teaching Contents}

\subsubsection{Classify the Knowledge Points}

Based on combing the knowledge points of the course, a gradual teaching content framework is set up, and the knowledge points are divided into declarative knowledge and procedural knowledge [5]. The declarative knowledge of color composition mainly consists of the theory about color, including the basic concept of color, the three elements of color, the tonality of color, the color shift and the contrast of color. The procedural knowledge includes toning, collocation, application of color, the composition of point line and surface of color, etc. The early stage of the course mainly teaches declarative knowledge, while the later stage teaches procedural knowledge, so the process is from theory to practice, step by step.

\subsubsection{Integrate with Specialty}

The author adds the chapter of color application in interior design in the teaching contents to empower students with design ability. In the form of a workshop, students are asked to research on color matching and finish a group-work of interior design of color matching, which lasts from concept to plan. This method plays a professional enlightenment role, at the same time links to the follow-up course of interior furnishings design.

\subsection{Renovating Teaching Methods}

\subsubsection{Introduce Modular Teaching Methods}

The author introduces the modular teaching method and puts it into practice. According to professional characteristics, learning situation, this course can be divided into four modules: theoretical knowledge, in-class exercises, teacher's comments and group workshop. Each module has its own emphasis on students' knowledge goals and ability goals, among which theoretical knowledge requires students to think rationally and master all kinds of knowledge points of color composition; in-class exercises require students to apply what they have learned; teacher's comments promote teacher's interaction with students and understand students' mastery and class style; group discussions push students to give full play to their ability to learn independently, to develop the ability to discover and solve problems, to grasp market trends, to understand the principles and functions of indoor color matching, to have team spirit, to develop hands-on skills, and to exercise their ability to express. Each class can have two to three modules for free "weaving "[6], to make sure that the class is rich in content, balanced with theory and practice, so as to arouse the enthusiasm of students.

\subsubsection{Employ Theme Teaching Method to Improve Student's Learning Interest}

One of the highlights of the curriculum reform lies in the theme of each class, that is, the knowledge points and assignment requirements of the course are all around the theme of this class. The theme design is shown in Table 1. The themes implanted in each class help improve students' enthusiasm for learning and break the boring practice. 
Table 1. Summary of the design themes of the course.

\begin{tabular}{lll}
\hline Arrangement & Class hour & Theme \\
\hline 1 & 4 & Basic Knowledge of Color Attributes and Color Shift \\
2 & 4 & Color Contrast \\
3 & 8 & Color Synesthesia: Texture of Color (Touch) \\
4 & 4 & Interpretation and Deconstruction of Masterpieces \\
5 & 4 & Color Synesthesia: Taste \& Color \\
6 & 8 & Color Synesthesia: Hearing \& Color \\
$7,8,9$ & 16 & Workshop: Indoor Color Matching \\
\hline
\end{tabular}

\subsubsection{Include Five Senses in the Teaching Method}

Another merit of the course reform is the application of synesthesia in teaching. Synesthesia design refers to the trigger of one sensory stimulus to another when designing interpretation or user experience. Successful design works can fully mobilize the user's various sensory [7]. By the link of synesthesia, students' learning enthusiasm, creativity and imagination are fully stimulated, and the students' associative thinking [8] are cultivated imperceptibly. In the second week of tactile texture, taste and color, hearing and color knowledge, the author asked students to bring along snacks, and invited students to listen to music while practicing. This seems to be against the school rules and may break classroom discipline, but on the contrary, this method promotes students' understanding and use of synesthesia, and achieved better teaching results, see Table 2 .

Table 2. Five Senses in Teaching Methods.

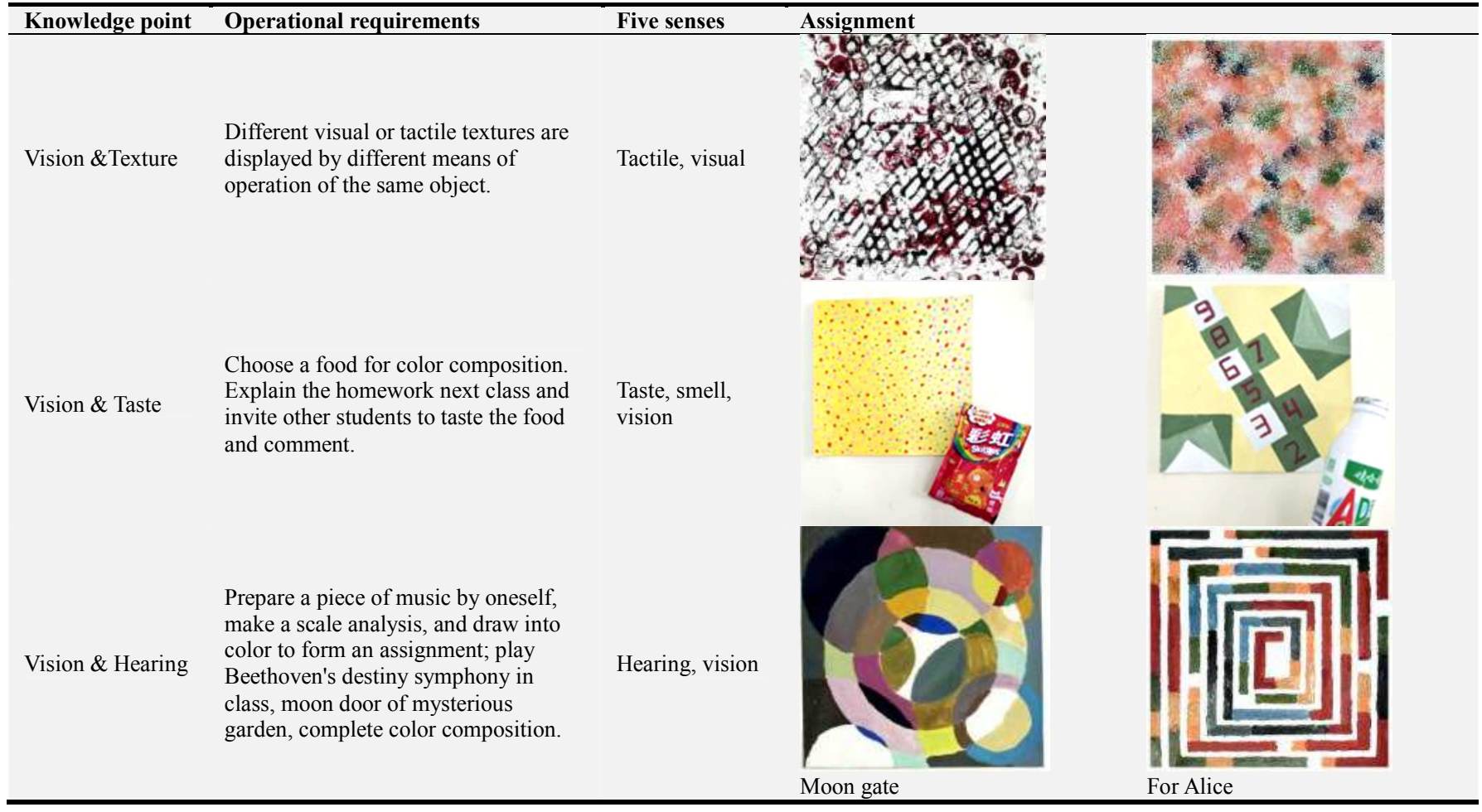

\subsection{Raising Teaching Arrangements}

\subsubsection{Combine Teaching with Practice}

"Color Composition" was a basic course which is not strongly applicable. This reform combines the knowledge of color with the major of environmental design, enlightens the thinking of space creative design through color [9], and pays attention to the cultivation of practical operation and application ability [10].

Combining-practice 1 is Classroom Experiment so to increase interest and consolidate memory. The basic knowledge of color science is relatively boring. Inspired by the Professor Bisson and Professor Duroni from Milan
Polytechnic University, the author designed many interesting small experiments in the course of color teaching, such as "negative image", "visual illusion", "appetite color" and so on. By doing experiments, it can arouse students' enthusiasm and help them understand and deepen their memory.

Combining-practice 2 is letting students contact the market as soon as possible. Finally, students will be required to participate in the workshop and complete the color matching. To finish this assignment, students need to accumulate certain professional knowledge, explore their imagination and try to apply the color composition in the space, which means the operation is difficult. Therefore, students need to carry out market research and preliminary investigation at early stage, and find inspiration and material source for the concept 
extraction of workshop, face the opportunities and challenges

research contents are shown in Table 3. of market [11], and make the homework professional. The

Table 3. Research Types and Contents.

\begin{tabular}{lllll}
\hline Research Contents & Research Time & $\begin{array}{l}\text { in-class or } \\
\text { out-of-class }\end{array}$ & Purpose of Research & Remarks \\
\hline $\begin{array}{l}\text { IKEA Model Room Survey } \\
\begin{array}{l}\text { Customer Research of } \\
\text { Workshop }\end{array}\end{array}$ & Weekend of week 1 or 2 & Out-of-class & $\begin{array}{l}\text { Understand the soft loading design, understand the role of } \\
\text { color composition in interior design }\end{array}$ & $\begin{array}{l}\text { Individual or } \\
\text { group work }\end{array}$ \\
\hline
\end{tabular}

\subsubsection{Assessment as Learning}

In order to optimize the evaluation mechanism, we need to reduce the weight [12] of summative evaluation and improve the weight of formative evaluation. Evaluation, as a very important part of the learning process, has gone through three stages: assessment of learning, assessment for learning, assessment as learning. "Assessment as learning" sees assessment as a part of learning, and is a scientific learning effect evaluation [13]. With the increase of the number of reviews, the author used witty and humorous online language to gain students' attention and interest. It has proved that this action can not only help students be aware of the differences between peers and themselves, but also bridge the gap between the teacher and students. Students are also required to introduce and evaluate their homework, and the participation of students in assessment is known to generate higher-order learning outcomes [14]. On one hand, teachers can understand the characteristics of each student. On the other hand, students can exercise their oral expression ability. After all, it will bring embarrassing situations if they show their dissatisfied homework in front of everyone. In addition, during the class, there are mutual comments between students, which often become discussions, and finally added with the teacher's summary [15].

The establishment of clear assessment criteria is helpful for teachers to give objective and fair evaluation and to consider students' analytical ability, learning attitude and comprehensive quality in all directions. Assignments, as the carrier of evaluation, can periodically reflect the teaching effect, thus assignments can assess whether the students achieve the learning goal. Therefore, the assignment should match with the learning goal. See Table 4.

Table 4. Matching Assignments with Learning Objectives.

\begin{tabular}{lll}
\hline Number & Assignment & Learning Objectives \\
\hline 1 & Color Ring Drawing & Knowledge of hue \\
2 & Color Shift Practice & Knowledge of brightness and purity \\
3 & Color Contrast & Master the tonality of color, the cold and warm of color \\
4 & Color Texture Practice & Practice divergent thinking, creative thinking \\
5 & Interpretation and Deconstruction of Masterpieces & Master color matching skills \\
6 & Synesthesia Practice & Inspire design and improve creative thinking \\
7 & IKEA Model Room Survey & Learn how to do design research; Learn how to match colors in interior design \\
8 & Workshop: Indoor color matching & Understand the method of the color mood board, make color matching plan; enhance \\
& & the sense of teamwork; practice program reporting ability, improve presentation skills \\
\hline
\end{tabular}

\subsubsection{Focus on Teamwork}

At the Beginning of the course, the author asked the students to form groups for the workshop by using the "draw lots". In this way, we break the student' small teams in the class so that students' mutual understanding can be improved and their communication expression ability can be enhanced. It turns out that students maintained good communication in the team, and finally had team cohesion and team spirit thus became more initiated in their study.

\section{Discussion}

\subsection{Comparison of Assignments}

Compared with the previous teaching model, the reform made higher integration with specialty. The Figure 2 shows that, the before the reform, students were required to complete the color composition on a carrier, such as the T-shirt design in 2015 and the stool decoration in 2016. Figure 3 shows the students' achievement of the workshop. From the assignment comparison, we can see that after the reform, the requirements for students had been improved. They no longer mechanically decorate an object with color composition, but achieve the results through brainstorming and teamwork, and complete the indoor color matching plan on the basis of understanding the color, texture, material.

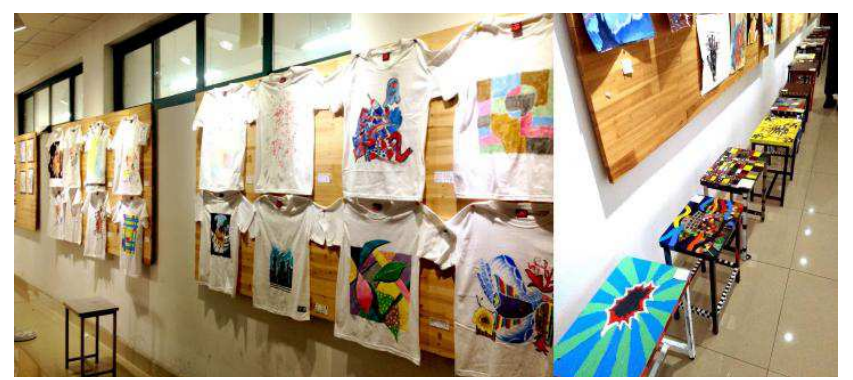

Figure 2. Students' achievement before reform. 


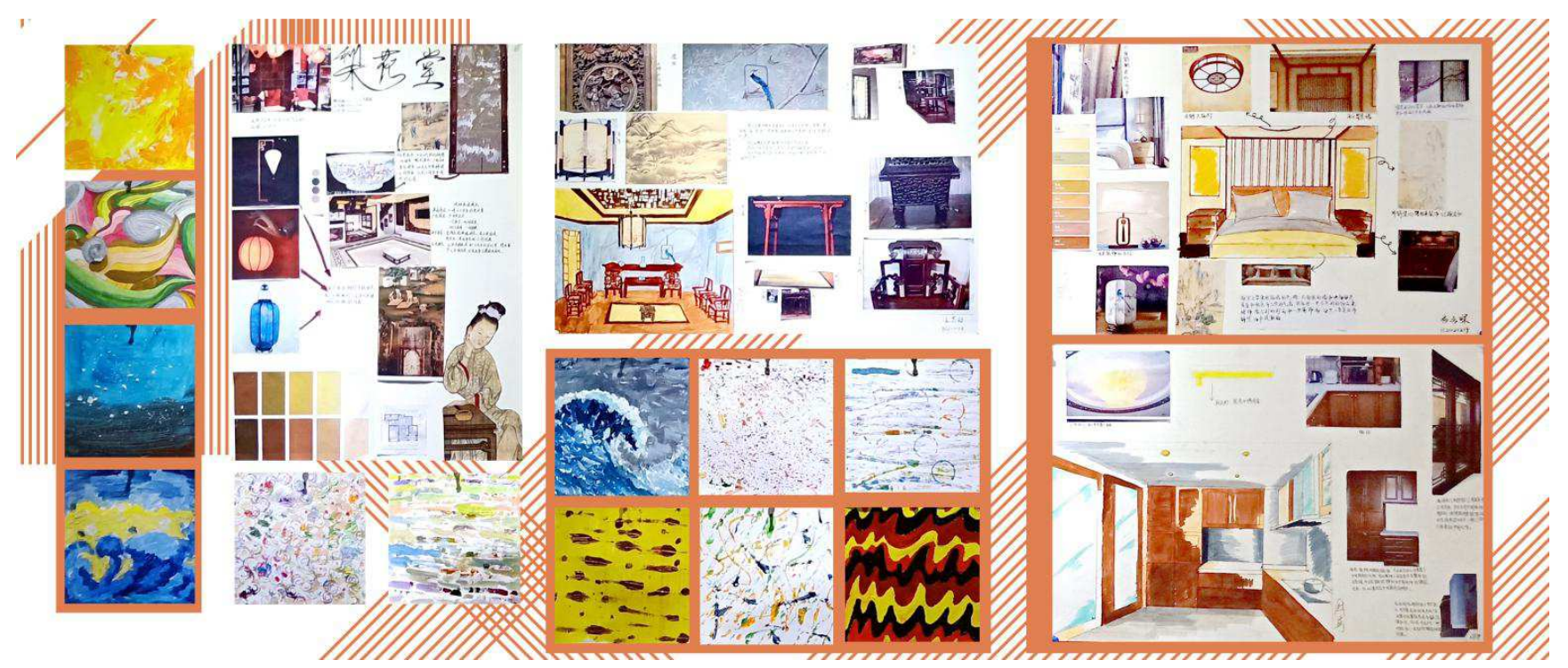

Figure 3. Students' achievement of Workshop.

\subsection{Questionnaire Feedback}

Questionnaires are used to reflect the result of the teaching reform. After the course, the author sent out a questionnaire to the students, a total of 28 students answered. This questionnaire demonstrated students' needs and feedback. Most students agree that the reform integrate knowledge with professionalism through the workshop practice, see Figure 4. They generally felt that indoor space color matching were more integrated with professional learning. Students liked to apply synaesthesia design to color design in particular. The synaesthesia design of the auditory and taste parts is highly evaluated, as shown in Figure 5.

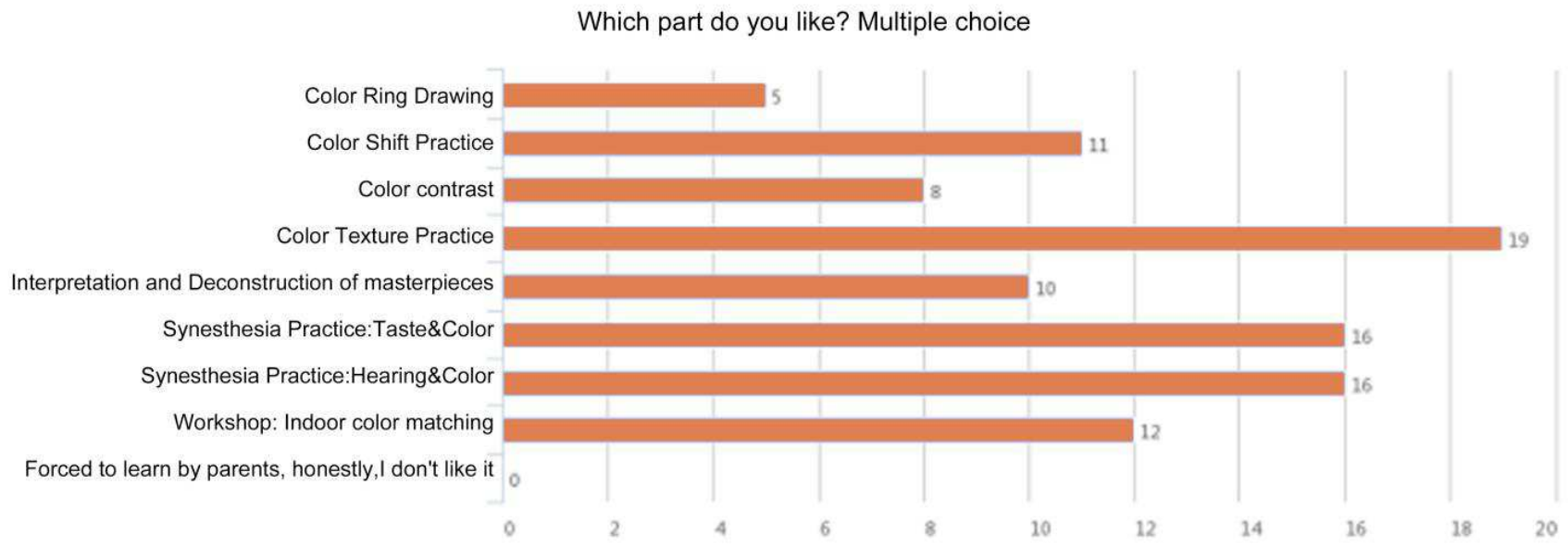

Figure 4. Students'feedback on favourite part.

Which part do you think is more connected with the major?

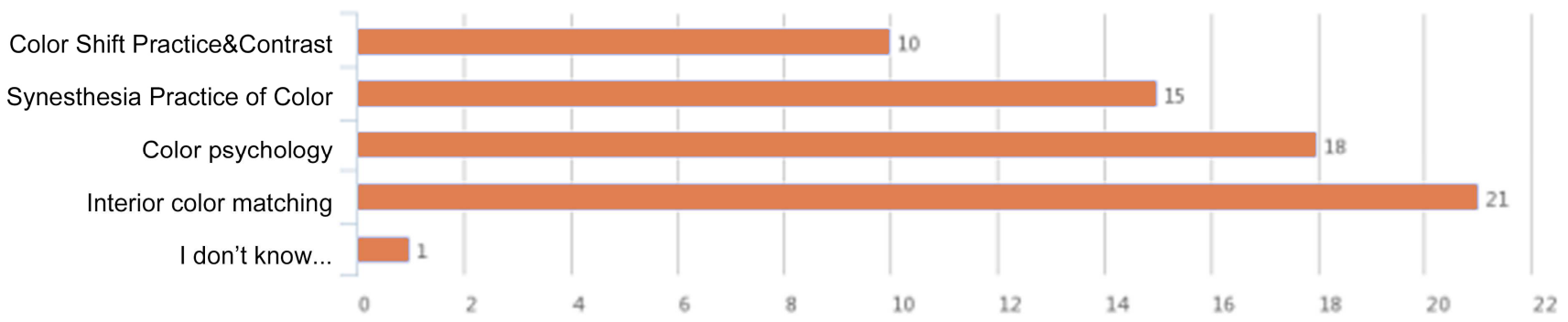

Figure 5. Students'feedback on speciality connection. 


\section{Conclusion}

From the above questionnaire, it can be concluded that the reform is effective and become more systematic and universal through 3R framework.

By refining the teaching contents, the teacher made the knowledge of color composition more systematic, and made the basic course more adaptable to the professional curriculum. raising teaching methods, this reform stimulated students' creativity and vitality, and strengthened students' enthusiasm for learning. By renovating teaching arrangements, this reform systematically solved the problems in the teaching of basic design course, so as to enhance the students' awareness of teamwork and increase the objectivity of evaluation.

Using the $3 \mathrm{R}$ framework for teaching reform is worth trying. In this course, I intend to integrate new teaching methods and teaching arrangements in the $3 \mathrm{R}$ framework, in the future, and combine current events in teaching content. Among other design curriculum reform, I plan to draw on the $3 \mathrm{R}$ framework to explore the teaching content, teaching methods and teaching arrangements.

\section{References}

[1] Liu Longzhen. Pay homage to Classics: Teaching Exploration of color composition in independent college [J]. Journal of Shandong Agricultural Engineering University, 2019 (12): 159-16.

[2] Asu Besgen, Nilgun Kuloglu, Sara Fathalizadehalemdari. Teaching/Learning Strategies Through Art: Art and Basic Design Education [J]. Procedia - Social and Behavioral Sciences, 2015 (182): 428-432.

[3] Yang Zhi, Zhou Xiu. A comparative study on the course of color composition in China, Japan and the United States [J]. Design art research, 2012 (01): 118-124.

[4] Wang Xueqing, Zheng Meijing: Fundamentals of two dimensional design $[\mathrm{M}]$. Shanghai: Shanghai People's fine arts publishing house, 2013.
[5] CERI B. Dean, Elizabeth Ross Hubbell, Howard pitter, BJ stone. Nine teaching methods to improve students' learning efficiency [M]. Beijing: China Youth Publishing House, 2013.

[6] Hilbert Mayer, Theory of Classroom Teaching Methods [M]. Shanghai: East China Normal University Press, 2011.

[7] Li Yicheng, Wu Wenjia, Jiang mu. Synaesthesia and synaesthesia in comprehensive design [J]. Packaging engineering, 2018 (06): 29-33.

[8] Shan Chunxiao. Innovative research on the cultivation mode of creative thinking in art design teaching of independent colleges [J]. Art education research, 2014 (01): 152-153.

[9] Ma Jun. Using color composition to inspire space creative design thinking: On the teaching art of color composition course for environmental art design major [J]. Art and design (Theory), 2012 (08): 151-150.

[10] Fan Hua, Yang Jingxuan, Luo Ping, Ma Shanshan, Xie Shimeng. Independent inquiry teaching of "practice leads to truth, learning is supplemented By Bishop" [J]. Laboratory research and exploration, 2020 (07): 158-163.

[11] Yao Danli. Thinking on the cultivation of innovative talents of environmental art design major in Independent Colleges and universities [J]. Art science and technology, 2014 (04): 416.

[12] He Chunmei. Process evaluation, achievement goal orientation and learning engagement: mechanism and path [J]. Exploration of higher education, 2020 (11): 36-4.

[13] Cheng Zhonglin, Xu Wenting. Exploration and practice of formative evaluation assessment model Based on superstar learning pass -- Taking calculus course assessment as an example $[\mathrm{J}]$. Science and education guide (late ten days), 2020 (05): 40-41.

[14] José-Luis Menéndez-Varela, Eva Gregori-Giralt. Ru Brics for developing students' professional judgement: A study of sustainaBle assessment in arts education [J]. Studies in Educational Evaluation, 2018 (58): 70-79.

[15] Sun Huixia. Research on the integrated teaching of design color and color composition in Basic design teaching [J]. Decoration, 2011 (10): 112-113. 